\title{
La Ciudad Muerta
}

\author{
POR QUE NO ME CASE CON FRANCINETTE
}

\author{
por Abraham Valdelomar
}

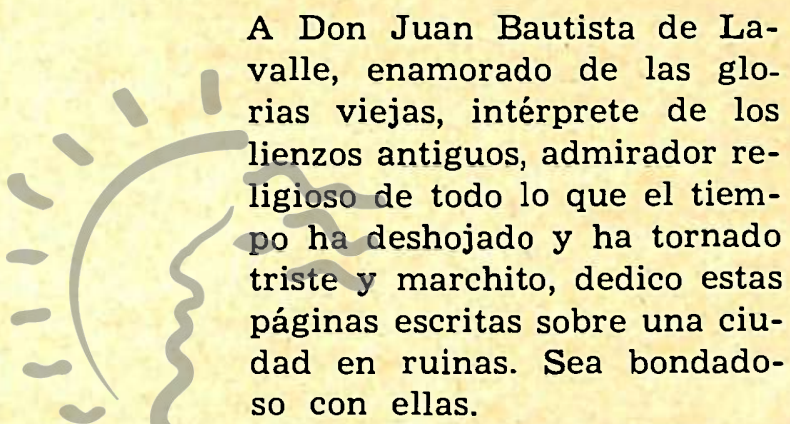

A. V.

Le passé c'est un second coeur qui

Il bat. Quand le silence en nous se

\section{(bat en nouse.ca de Ietras}

cette pulsation mysterieuse est lá

qui continue... et quand en réve il

(bat encor,

et quand en souffre il bat, et quand

(en aime il bat

toujours... C' est un prolongement

(de notre vie...

Henry Bataille

\section{I}

En el "Atica", sobre el mar de Río Janeiro, Brasil, febrero 12 de 1911.

Adorable Francy:

Todavía me arrepiento de haber dejado bajar á tierra á ese hombre, pero le echo la culpa a la luna. Es ella la cómplice de todos los crímenes y, en muchos casos, la instigadora. Esté usted 
segura, mi adorable Francinette, que cuando ella tiene esas notas de luz casi verdes como si se copiara á través de una falsa esmeralda, algo extraño está pasando sobre la tierra. Yo soy médico y he podido observar el efecilo de esas nubes de luna en esos enfermos de locura y en los alucinados, en los criminales, en los neuróticos, en los artistas. En los artistas sobre todo.

La luna de Pierrot es una luna blanca y redonda, vulgar y buena, pero Pierrot no mata. La luna de Salomé, la luna bíblica, es misteriosamente bella y bajo su luz pecadora besa los labios ensangrentados de Jokanahan. A veces creo, encantadora amiga, que la luna que brillaba sobre C" " no era la luna que iluminó los caminos del Señor, ni la que bañó de plata los trigales del Egipto, ni la que se copiaba en el lago cuando se forjó la leyenda sublime del Imperio del Sol. Esa luna ha debido ser la luna de Venecia de los Dux, la que alumbró á los fundadores de Inglaterra, la que dió su color á Catalina II y guía hacia el amor al barco nacarado de Marco Antonio. Cómo me vienen a la memoria los versos de este admirable espíritu:

"Dime oh reina de la noche si en tu lánguido semblante palideces hoy de vicios o blancuras de inocencia".

Si Ud. - ¿se acuerda? - en el saloncito del Continental, cuando estábamos de novios, no me hubiera contado el motivo de su viaje á América, yỏ me habría casádo tamiga mía, porque la amaba entrañablemente, la amo aún. Mi amor. Francy, ha salido de una tonalidad infinita y única. ¿Por qué me lo dijo usted en vísperas de casarnos, cuando hacía ya quince meses que nos conocíamos? Después de aquella noche no debíamos vernos más. Entre nosotros se elevaba sombría, siniesirci la figura de Henri. Y usted que ignoraba, que ignora todavía la hora negra.

Es necesario que conozca esta horrible verdad para que disculpe mi conducta que á no escribirla esta carta no sería la de un caballero y crea usted Francinette que lo he sido y lo seré siempre. Aquella noche - ise acuerda? - la luna estaba casi verde también. Usted quiso hacerme una confidencia á la que tenía derecho porque debíamos casarnos ocho días más tarde y empezó a contarme cómo había usted conocido a Henri desde niño, cómo habían crecido casi juntos y cómo, antes de casarse, Henri pensó en su viaje á América rentado por su editor después de su novela "Misterio" y cómo al volver a Francia debían ustedes casarse y pasar la temporada en Ostende. 
Luego se ensombreció su rostro y dolorida me dijo usted que Henri no volvió nunca a Francia, que su última carta la recibió usted fechada en $C^{\prime \prime \prime}$, donde yo viví tanto tiempo, sin saberlo usted, y que abandoné para radicarme en $\mathrm{M}^{\prime \prime}$ " donde nos conocimos. Es, concluyó usted, el motivo de mi viaje; pero estoy segura que yo no encontraré jamás á Henri en el mundo, lo he perdido para siempre. Después - no me olvidaré nunca- nos despedimos. Eran más de las once y yo tomé el barco aquella misma noche para viajar siempre, viajar eternamente, lejos de la paz de las poblaciones que me recuerdan á Henri y de los puertos encantadores que me la evocan á usted, Francinette.

Ahora le escribo desde la alta mar que baña Río Janeiro. Pronto llegaremos al puerto donde dejaré esta carta. Llegará?... No llegará. Por lo menos yo la habré escrito. Ahora haga ánimo $\mathrm{y}$ escuche mi relato.

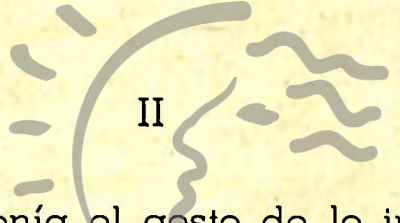

Henri D' Herauville tenía el gesto de lo insondable. Usted lo sabe: todos los hombres de gran talento tienen un gesto particularísimo. Hugo tenía un gesto de fiera acorralada: en él eran los ojos de Byron, el delinsaciable, el gesto de los golosos de amor no satisfechos nunca. Sarah, el gesto de toda su raza en éxodo, una mirada nómada, casi bíblica.ul Mẻnaelssohn, velrde 'la pavura. Cervantes, el de la seguridad. D.'Annunzio, el del convencimiento.

Henri había venido á C" " el puerto, por conocer la ciudad vieja que se extiende detrás, á tres kilómetros del mar. Yo era médico en C" "y tenía que recibir el barco. El "Jeroboam" llegó á la bahía á las doce en plena noche, con un mar agitadísimo y con una patente sucia. Opté por no recibirlo y dejar en cuarentena el barco. Estaba en el camarote del piloto, habiendo salido éste, cuando se acerca á mí un caballero y me dice en español con marcado acento francés;

-Es usted, señor, el médico que debe recibir el barco...?

-Si, caballero, pero pienso no recibirlo. Trae sucio el patente...

- Necesito bajar a tierra esta misma noche, doctor. Debemos estar pocos días - tres o cuatro- y si estos los gastamos en arreglar el patente, no podré conocer la ciudad vieja ni los subterrá- 
neos; y créame que me mortificaría mucho haber dejado mi partida de poker en el Jockey Club y mis sesiones frente á la columna Vendome para conocer los subterráneos de una ciudad colonial de América y no poder llegar á ellos...

- Usted es parisién?

- Francés, pero no parisién. Ha debido usted alguna vez leer mi nombre -agregó el caballero sonriendo-. Me llamó Henri D' Herauville.

-D' Herauville?... Oh, si he leído sus libros...

-Bajaremos, doctor?... (¿y la patente sucia?).

-Bajaremos, caballero.

Y esa noche ocupaba tranquilamente un departamento del Insular-Hotel, después de haberme invitado á cenar. En la cena se limitó á pedirme ciertos datos y concluyó aquella dándome un apretón de manos: drá usted?...

-Vendré, señor $D$ Herauville...

Aquella noche saqué del armario "Misterios" de mi nuevo amigo y leí casualmente la página del silencio. Aquel hermoso capítulo que usted conocerá, Francinette; ese artículo de las perspectivas, de las proporciones y de los gestos; aquella pintura de Little Tich tam intensáa yeam gráfica del silencio, que el autor de "El Cuervo" no la habría soñado mejor. Usted sabe las imágenes macabras, lorrenescas que provoca el libro de Henri; los locos serían capaces de volver á la razón con sus narraciones.

Al día siguiente, viernes, fuí al Hotel Insular. Ya Henri me esperaba, pero aún estaba en caina. Me hizo entrar. Se desperezaba en el lecho pero bien se conocía en sus ojos que no había dormido tranquilamente.

- Coja usted un cigarro de la petaca, -me dijo-son egipcios auténticos. Estoy seguro que no los ha fumado mejores. Entre tanto yo me levantaré; el baño me espera en la otr'x habitación. Usted proceda como en su casa.

Se había colocado un kimono de seda gris y unas pantuflas bordadas. Sacó de la maleta abierta sobre el sofá, polvos, frascos y cepillos y haciendo una graciosa reverencia se perdió en la habitación contigua:

Entonces junto a la maleta vi varios libros y encima de las ropas un dije raro y curioso. Un esqueleto de marfil viejísimo que 
tenía sobre la cabeza una antorcha ardiendo. El fuego eran varios rubíes que rodeaban á uno de gran tamaño ¿Conoció usted este dije, Francinette?... Poco después regresaba Henri.

-Qué tal el baño, señor mío, le dije.

-Agradable. La luz del cuarto mala. Pero hablemos de C" " y de la ciudad vieja mientras hago mi toilette.

- Con una condición.

- Cuál?

- Que desista usted de ir á conocerla...

- Pero cree usted en todo lo que se dice de la ciudad?...

- Si le refiero lo que sé de ella, me permite usted no ir?

- Según lo que usted me refiera, doctor.

- Creo que le convenceré.

Yo le dije:

III

LA CIUDAD COLONIAL

- Campo de gules. Tres estrellas y en el centro una corona real. El escudo es de forma romana y termina en un penacho de tres plumas doradas y la leyenda "Hic est Stella regis". Esta es la estrella del rey. Como usted sabe fue una poderosa ciudad tan orgullosa y celebrada que se diría que el tiempo ha querido castigar su orgullo como a una mujer coquetanverso"

- Cuando cayó?...

- Estas ciudades, amigo mío, se fueron con la dominación hispana. Estas ciudades netamente españolas no podían vivir la delictuosa época de la República. Eran como esos nobles arruinados que, perdida la hacienda, se pegan un pistolazo sobre el mismo tapete, antes que hacer una vida humilde. Nobles sin hacienda o damas aristocráticas que se niegan a lucir pobres en los saraos los restos de su pasada grandeza.

La independencia, palabra inventada para matar reyes y destruir recuerdos, mató á muchas de esas ciudades coloniales nobles y florecientes. Algunas dejaron que los mulatos independizados, los soldados ensoberbecidos, los criollos opulentos, pisotearan sus escudos, hollaran sus blasones y deshojaran sus lises de oro, mas esta que á nuestros pies duerme el sueño de la muerte perteneció á las rebeldes, á aquellas que como Saúl se arrojaron 
sobre el filo de su espada antes que ver la humillante sonrisa del vencedor...

- Luego es una ciudad que murió íntegramente colonial?...

- Sí. El hálito de la república, que estallaba como un fermento, no logró invadirla. Tal es hoy, como fue con el último virrey y con el último prelado que visaron las armas reales. Verdad que hoy sólo queda de tanta gloria el cadáver de la ciudad y uno que otro apellido ilustre rodando por el mundo...

Entre esos muros terrosos y caídos, entre esas palideces de polvo, bajo esos techos derruidos, se dieron un día las fiestas más espléndidas. Por esas escalas que hoy nadie transita, ascendieron cortes de virreyes con capas bermejas, espadas de oro y damas blancas como lirios. Por sus calles silenciosas y despedradas hoy, pasaron los caballeros y las calesas; éstas con su tren dorado, sus caballos forzosos y sus portezuelas selladas, aquellos con sus sombreros de picos, sus enredadas largas piernas y su trenzada cabellera rubia, mientras á través de los biseles transparentes se esfuma el rosa de las mejillas empolvadas sobre el terciopelo, como un desmayo de colores.

Conoce usted esta evocación de la ciudad?... Escuche:

\section{LA BVocacion DE LA CIUDAD DORMIDA... "Jorge Puccinelli Converso"}

Por la ciudad en ruinas todo invita al olvido... los viejos portalones y la plaza desierta, el templo abandonado... La ciudad se ha dormido... ¡No hagáis ruido .... parece como que se despierta.

Una sombra se esfuma bajo los portalones y se pierde en el templo donde ha muerto el sonido de los lánguidos kyries y de las oraciones, $y$ en medio del silencio de sus meditaciones, la ciudad se ha dormido...

Las escalas de mármol que ascendieran antaño los nobles con escudos de lyses y de estrellas, ocultas desde entonces tienen cada peldaño y ahora jpobres escalas! nadie sube por ellas. 
Las sombras de las damas de las venas azules y manos transparentes, cuando agoniza el día, lloran entre la sala donde rieron sus tules la tristeza infinita de la sala vacía.

$Y$ quedan los recuerdos que son como trofeos sedosos miriñaques y mitones bordados, calados abanicos y griegos camafeos que plegaban las telas en los hombros rosados.

Y los trajes sedosos brillantes, como soles, que las damas lucieran en noches virreynales enhebrados en perlas, con luces tornasoles, largos como las colas de los pavos reales.

Pasa sin hacer polvo llevando á un caballero bajo el arco que forman los frisos de la puerta la calesa que guía el viejo calesero en la empolvada ruta de la calle desierta.

Todo marcha en silencio con la luna de estío hacia el viejo palacio de los inquisidores. La luna castamente se copia sobre el río y se disipan estos luadros evocadores....S

Por la ciudad en ruinas todo invita al olvido... los viejos portalones y la plaza desierta, el templo abandonado,... La ciudad se ha dormido... ¡No hagáis ruido! ... parece como que se despierta...

- Sí, si señor D' Herauville, por allí, por las calles de esa ciudad muerta pasaron los soléados del rey, las músicas de los clarines, los caballos espumosos y violentos, de largas crines y serenas colas; los pregoneros de dulces de azúcares blancos y de almendras y de frutos de nogal almibarados y tiernos; las tapadas de ojos incendiarios, las damas de la corte, las criollas riquísimas que hacían de sus trajes obras de arte y de tiempo y los severos administradores de justicia, los reales oidores, los guardadores del tesoro.

Y en esas noches de luna que hoy ven la ciudad muerta como el cuerpo abandonado de una amante en desgracia, cuántas 
citas de amor tras de las rejas, cuántos caballeros caídos de una estocada, cuántos virreyes disfrazados salvando muros, atravesando frondas de granados en flor y de naranjeros y jazmines para llegar á la ventana estreabierta ó á la celosía de una noble Julieta.

Esos palacios, que no otra cosa eran, y en los que bajo el es. tucado de los techos ó las alegrías de los cielo rasos pendían arañas monumentales con bujías rosadas, en esos salones donde habían amorcillos, marquesas y nobles perfiles en relieves dorados, vitrinas que encerraban San Josés y baratijas, vírgenes y amuletos, frutas maduras enhebradas en hilos de oro, nísperos forrados en papeles de plata y negritos vestidos de boda.

Aquella noche no se por qué, Francy, venían a mí los recuerdos con más claridad y fijez@. Mi imaginación evocaba mejor que nunca la ciudad colonial y le seguía contando a Henri:

- Hay un arco truncado, le decía, donde termina la población. Era el arco triunfal bajo el que entraban á la ciudad sobre ladrillos de plata maciza y hierbas aromosas los virreyes y su corte, los arzobispos y sus morados familiares. Las damas aristocrática les arrojaban flores y hacían pender de los barandales de sus balcones tapices finísimos y mantones bordados.

Y los trajes. Sedas purísimas, velos transparentes hoy descoloridos por el tiempo, con piedras incrustadas en derroche como en los modernos cuadroside Mancini, que "son verdaderos joyeles. Gorgueras impecables, mitones de hilos inverosímiles, miriñaques, abanicos de marfil y gasa con amorcillos y mariposas, camafeos que juntaban pliegues sobre hombros de rosa, peinetas monumentales del color de las cabelleras y, sobre todo aquello, un par de ojos con visiones de Versalles y un par de labios con sentencias horacianas.

Imagínese usted D' Herauville la ciudad viva. Son las cuatro. En casa de los marqueses se toma la comida de la tarde. La vajilla de plata, signada con escudos reales, ofrece en sus fruteros manzanas pudorosas, melocotones aterciopelados, nísperos rojos, lúcumas como yemas de huevos y granadas reventando como cofres de rubíes. Las granadas maduras! Joyeles de vinos de las piedras sangre, las piedras labios, las piedras heridal

¿Conoce usted la evocación de las granadas. Ahora están descoloridas, pero en un tiempo fueron rojas. 


\section{LA EVOCACION DE LAS GRANADAS}

Orgullosas y frescas se elevan juntas sus coronas, coronas de cinco puntas que va á ofrecer abril, cúpulas en que rojas flores marchitas duermen; y que se elevan como mezquitas por donde el fruto se va á abrir...

Las Granadas redondas como joyeles son ánforas que ocultan líquidas mieles, como la sangre del rubí, y ofrecen á los ojos formas poliedras talladas y bermejas, líquidas piedras en rota esfera de marfil...

Triunfando en el tranquilo follaje espeso cada fruto es un labio que ofrece un beso bajo la sombra del jardín.

Y las que aún no maduras crecen cerradas son los redondos pechos de las amadas que nos reserva el porvenir...

A hora, amigo miól mécimagino ven llegar á los saraos á los nobles en sus calesas doradas y desfilar ante los cuadros de Rubens.

Los cuadros de Rubens que tienen el claroscuro de esas épocas lejanas que se ensombrecen con los tiempos inquisitoriales y lucen por las épocas de fasto, de boato y de grandeza, por esas fiestas que no volverá á ver la historia.

En el centro se eleva el Tribunal caído de la Santa Inquisición. No es verdad que había mucho de justicia en aquellos santos oficios? Quemar á los infieles, á los herejes, á los hechicerosl Había á través de esas crueldades un profundo amor á la Historia y al Pasado. Los severos inquisidores amaban, más que nosotros, aquellas cosas. Para ellos deshojar el encanto de las creencias, deshacer el pasado con un estudio arqueológico, quitar la gloria á un personaje de otros siglos porque se hubiese descubierto una nueva verdad, eran crímenes horribles. Ni la verdad valía tanto para ellos como el Pasado, archivo de recuerdos de esta vieja Humanidad. 
$Y$ en verdad señor $D^{\prime}$, Herauville bien vale que queden las cosas como están, como hablaron á nuestros padres y á nuestros abuelos. Amar el pasado es como alargarnos más la vida... Qué importa que Homero no sea el cantor heleno, el aeda ciego y errante?... Llamemos Homero al que haya sido el cantor. Ya el poeta no es el hombre que se arrastraba en Grecia sino al símbolo de una música sublime que se eleva sobre el mundo, sobre la Raza y sobre el Tiempo.

Dejemos al heleno poeta, al sajón filósofo y al Inca de las narraciones. Garcilaso, Shakespeare, Homero. Qué importa que se llamasen Volera, Bacon, Kalikrates...?

¡Y si usted señor D' Herauville viera los cuadros! Allí hubo Murillos de formas celestiales, Velásquez de caballos panzudos triunfadores, Riveras. Pero esos cuadros quedan como cadáveres que han vivido la misma vida de esas damas jóvenes y lindas que después, al casarse, alfombraban la calle desde sus señoriales mansiones hasta la puerta del lemplo, de esas damas que después fueron abuelas y que ya viejas se entregaron en cuerpo y alma al pincel de un gran evocador Ignacio de Merino. Estos versos son casi lienzos robados al gran pintor!

\section{Bibaievocacion DE LLASABUELAS}

Yo virentre la negra sombra de las telas cual suave conjuro de Hada Melisanda entre terciopelos, las nobles abuelas reir en sus golas de telas de Holanda.

Sus labios el fino divino Merino pintó con la sangre bermeja de bueyes en tono tan suave, tan rosa, tan fino... ¡Oh aquellas abuelas de rostro divino que eran el encanto de los visorreyes!

Las manos exangües que besan los velos son el fiel transunto de las regias manos que entre las caricias de los terciopelos pintaron las tintas de los castellanos al pintar las manos de reyes abuelos. 
El oro amarilla los viejos blasones

$\mathrm{y}$ en los pechos graves insignias de reyes

y orla ricamente los decamerones

de los finos lienzos cuyas gradaciones

eran el encanto de los visorreyes.

Los pies hebillados, los hilos del pelo contarse pudieran besando las golas $y$ el sedoso regio y azul terciopelo que aristocratizan en, el lienzo abuelo aquellas liliales damas españolas.

Líneas azulinas que en sus manos finas proclaman augusta prosapia de reyes, las sangres bermejas, las bocas divinas, los pies hebillados de aquellas meninas que eran el encanto de los visorreyes.

Los ví entre la negra sombra de las telas cual suave conjuro de Hada Melisanda. ¡Que nobles reían aquellas abuelas en sus golas blancas de telas de Holanda!

D' Herauville me èscuchába cen esa feligiosidad que después vi en él cuando bajabg el subterránepi Y que usted, Francinette, le había conocido.

Tomamos el desayuno hablando dè cosas diversas. En seguida invité á Henri á dar un paseo por los malecones y los muelles y á almorzar en mi casa. Henri accedió á mi invitación y ella se cumplió íntegramente. Era el viernes doce de Febrero. Después de almorzar debía yo ir á despachar y recibir un barco mercante y sólo podía estar con él á las cinco. Así se convino y que Henri se quedaría en casa leyendo o escribiendo en la biblioteca.

Todavía después del almuerzo charlamos bastante en el mirador de casa. Desde allí se veía el mar inmenso, la bahía llena de mástiles y la población a la que el calor intensísimo daba un ambiente de ensueño. D' Herauville me hizo repetir algunos versos...

A lo lejos se balanceaba rítmico el "Joroboam". Reinaba en el puerto un profundo silencio y las olas lamían la orilla produciendo un manso ruido de sedas. Entonces bajé en la paz inmensa de la tarde y á poco surcaba el mar en dirección al barco mercante. 


\section{IV}

\section{LA HISTORIA DEL ROSSO}

Comimos en el Insular frente á unas mejicanas bellísimas. Después de la comida les ofrecimos un coche y un paseo en la ciudad por el barrio de los extranjeros. Aceptaron. Nos fuimos deslizando entre alamedas que parecían litografiadas y entre mujeres elegantes con esa elegancia de los grabados de Gosé. En el puerto se come á las cinco de la tarde. Después del paseo, á las seis, dejamos á nuestras amigas y Henri quiso dar un paseo á pie.

- Vamos hasta la portada del norte - me dijo.

- Vamos; estoy a su disposición.

$Y$ caminamos charlando de la ciudad en ruinas.

- ¿Insiste usted en visitar las ruinas, señor mío? -le dije.

- Es mi único objeto. No siempre se puede hacer un viaje á América. No creo, por otra parte, que sea cierto lo que se dice. Los fantasmas americanos respetan a un francés... Pero se dirían que tiene usted miedo, doctor...

- Tal vez... Y esto me presenta ante usted como un mal médico y un vulgar hombre. No es tolerable, piensa usted, que un hombre que se halpasade la vida entre libros científicos tenga miedo de aparecidos. Bien está pero hay casos innegables. Son varios los que se han quedado en esos subterráneos: todos los que han bajado.

- ¿No han vuelto más?...

- ¡No!. El señor Lawrence, jefe de los ferrocarriles del sur, bajó con su esposa en 1890. Un pintor saboyano, Rosso Benedetti en 1898. La baronesa Misrahael, compatriota de usted y un señor Berthiel ó Bertleliel, no recuerdo bien, en 1899. Desde esa fecha sólo se sabe del hijo del gobernador civil, Eleo Sans. Todos han desaparecido y nadie ha podido dar con rastro alguno. Ya antes de ahora se hablaba de otros casos y se citaba a un fraile franciscano, á un judío y a un viajero francés...

- Pero eso es demasiado concreto... ¿Usted que los conoce de cerca, ha visto algo?...

- Conozco el caso de Rosso Benedetti. Es la historia más original y la he visto tan de cerca que le suplico señor D' Herauville que no baje... 
- Cuente usted el caso.

- Escuche. Rosso Benedetti, pintor de la nueva escuela, pasó casualmente por C" ". Quiso conocer las ruinas de esta ciudad, y aquí, en el puerto, encontró uno de los murillos extraídos de las ruinas, hace muchísimos años. Rosso se hizo grande amigo mío. Tengo, bien escondido por cierto, el boceto que me pintó en casa, es una joya que nunca mostraré y que á usted sólo $D^{\prime}$ Herauville enseñaré.

Rosso tenía predilección, adoración, por un idolito de palo santo, modelado, según él, por Torcuato Pini, escultor florentino de las Borgias. El ídolo representaba una virgen con el niño en los brazos, todo en un solo trozo de madera de doce pulgadas. Efectivamente la escultura era un prodigio. Rosso la llevaba consigo y jamás se había separado de ella desde que su madre se la puso en las manos. El creía que cuando se separaba de ella, algo malo le pasaba.

Una tarde Rosso quiso ir á las ruinas y, como usted, bajar á los subterráneos. Hice lo posible por disuadirlo de su empeño.

- Vamos - me dijo- me deja usted en el cerro.

Yo consentí. Desde el cerro que divide la ciudad del puerto se domina perfectamente las ruinas con su anteojo. Así pues le acompañé. Subimos el médano y al doblar sobre él para descender á la ciudad, me dijo:

- Espéreme hasta las cinco. Son las cuatro apenas. Si no regreso hasta esa hora guedecusted hacer como quiera, mas - dijo sonriendo- si como dicen no se está allí muy á gusto, daré golpes en los muros hasta que venga usted por mí. Adiós.

$Y$ se fue Rosso tranquilo hacia las ruinas mientras yo le veía alejarse claramente desde el cerrito de arena con mi anteojo.

Pronto llega. Examina una construcción, pasa por un templo, se interna, luego sale y se dirige al centro. Ahora se pierde de vista en unas callejuelas pero reaparece por el lado del río, pasa el puente y ya lejos, más pequeño, llego á mirar cómo saca un papel del bolsillo, lo consulta, lo guarda, destapa en la plaza la entrada del subterráneo, me mira desde allí, y me hace un saludo con el pañuelo. Le contesto y luego principia á bajar un escalón... otro, luego otro, otro, otro... y desaparece en el suelo.

Entonces principio á esperar. Son las cuatro y veinte minutos. Espero, espero. Ya me parece que va á asomar la cabeza rubia del buen Rosso, ya pienso que se ha perdido en la obscuridad. 
Las cinco! Rosso no ha vuelto... Principio á temer... Dudo. ¿Se habrá perdido Rosso?... Espero. Las cinco y cuarto. Rosso no ha salido aún. Entonces verdaderamente nervioso me decido a bajar e ir acercándome prudentemente en la ciudad en un indescriptible estado de ánimo. Bajo. Principio á entrar en las ruinas. Aquí pasa algo horrible, D' Herauville. No puedo dudar que lo sentí aunque pudo ser resultado de mis nervios excitados. En una piedra enorme cerca de una casa caída me siento a descansar, á limpiarme el sudor de la cara pero joh, que impresión! saco mi pañuelo cuando ¿qué cree Ud. que sentí?. Los golpes, señor D' Herauville, los golpes. Los golpes de Rosso abajo, profundamente abajo, en el seno de la tierra. Un frío intenso me bañó. Créame usted, tenía miedo. ¿Debía avanzar para buscar al amigo?... Debía arriesgarme en un misterio insondable y negro para buscar á Rosso?... Tal vez si; pero yo no tuve valor para hacerlo.

Por otra parte ya eran lás seis, el cielo, como ahora, enrojecía, y yo, sin discutirlo, tomé el camino de vuelta. Llegué a mi casa jadeante, delirando; estuve doce días en cama con fiebre alta y sintiendo por todas partes los golpes de Rosso sobre el muro. Entonces cambié de cása y me vine á vivir al hotelito que usted conoce donde traté, viviendo acompañado de una linda muchacha, de olvidar. Nolpodía estar tranquilo. mis recuerdos y mis nervios eran mis peores enemigos: Por fin curé un poco, cuando supe, un año más tarde el cciso de la señora Misrahael y del señor Bertleliel o Berthiel, entonces, no sé porque me sentí más tranquilo; tal vez, si fue, porque el caso de estos hacía olvidar y evitaba comentarios sobre la desaparición de Rosso.

Pero no había de terminar aquí mi mortificación. Una mañana, seis años más tarde, amanezco neurótico. Un temor de algo que no conocía me invade. Todo me da recelo. Pienso como si, de una habitación oscura fuese á salir un hombre para asesinarme. Salgo de mi casa. Voy al Insular y encuentro á la, señora Bretigne con sus dos niñas: Claudine y Fiorenze.

- IOh señor doctor, llevadnos a la playa! Queremos coger conchas! Llevadnos doctor, seremos buenos, ¿verdad Claudine? - IOh si! Llevadnos, dile Fiorenze, que nos lleve!

Las rubias chiquillas me ofrecían una ocasión para disiparme. - ¡Bien! iremos; pedid permiso y dad un beso a mamá. 
Bajamos, yo entre las dos y cogiéndolas de las manos, las escaleras de madera del Insular, que dan a la playa, y nos alejamos sobre el arenado húmedo que besaban las olas desmayándose. Pronto nos alejamos del hotel y yo me eché sobre la arena mientras las chiquillas jugaban. Me había abstraído completamente. Detrás de mí, yo miraba hacia el mar, se elevaban las rocas musgosas que sangraban agua cristalina, Claudina hacía un castillo de arena húmeda y lo reconstruía cuando la ola se acercaba á sus frágiles muros, mientras Fiorenze, cerca de las rocas, cogía conchitas, huesos blancos de aves marinas, plumas, y formaba un montón de deshechos sobre su mandil.

Yo pensaba. Dejaba correr mis ideas sobre el mar inmenso y oraba con la naturaleza con toda tranquilidad que solo dan las playas solas y abandonadas. Apenas se veían lejanos mástiles de los barcos mercantes en la bahía. De pronto un grito estridente, extraño, horrible, suena á unos treinta metros, y la niña Fiorenze que lo había proferido, se lanza hacia mi, despavorida y blanca.

- ¡Señor doctor! Allí hay un horrible animal! Le he visto, señor doctor, un animal, ven Claudine. Y la niña casi loca me apretaba las piernas dejando caen sus objetos. Yo, de pie, estaba absorto. La cosa era tan imprevista que no dije nada. La niña lloraba desesperadamente. Yo pensé en un ataque nervioso, por un exceso de dulces; in tmal frecuente de los giños, la examiné, y al tomar el pulso de la niña ¿qué cree usted Henri que tenía en la mano? Es horrible. jTenía la virgencita en madera de Rosso!... gido?...

- ¿Dónde has cogido ésto?... ¿dí Fiorenze, dónde lo has co-

- Allí, entre las piedras. ¡Allí hay un animal, señor! Yo quiero ir con mamá y Claudine...

- Iremos. Dóncle está el animal? - le dije pálido- llévame donde está!

- ¡No, no! No vayamos señor, y ante la idea de volver á aquel sitio, la niña sufrió un ataque de pavor horrible.

No quedaba más remedio que volver y volvimos. La niña se enfermó y mucho costó curarla. Ahora, señor D' Herauville ¿quiere usted ir á las ruinas?...

La tarde había terminado y apenas quedaba sobre el mar un poco de la sangre del Sol. Yo estaba tan nervioso que se me notaba en la cara, pues Henri, regresando de la portada del nor- 
te, donde hacía rato descansábamos, -me dijo-- levantándose pensativo y tomándome del brazo:

- ¿Hay luna esta noche?

$-\mathrm{Si}$.

- ¿A qué hora alumbra?

- A las doce más ó menos.

- Entonces regresemos; lo he pensado mejor.

- ¡Oh! Cuanto le agradezco que no baje! En fin, otro día, cuando se conozca el misterio.

- No. Bajaré.

- ¿Cuándo?

- Esta noche. Usted vendrá conmigo. Pero como me hacen falta algunas cosas, es necesario comprar en el puerto dos o tres kilómetros de cuerda, para bajar. Y sin querer darle mayor importancia, me propuso tomar un coche, ir por nuestras amigas, invitarlas á un té en el Insular o en el barrio de los extranjeros y terminó cantando su canzoneta favorita.

¡Oh láu- lá, las jovencitas!

Es al baile donde vamos

a bailar bellas cuadrillas, con los chicardos que amamos

Boh lautelá las jovencitas

Jes el baile donde cramosh so"

\section{V}

\section{LAS LOCALIZACIONES CEREBRALES}

A las once y media habíamos terminado nuestra invitación con las mexicanas. Ellas se fueron al "Caffe Romain, baile y música" y yo y el ilustre pasajero del "Jeroboam", tomamos por la recta de la portada del norte, donde se inicia el camino á las ruinas. ¿De dónde saqué valor aquella noche para hacer tal excursión? No lo sé, Francinette. Aquel hombre tenía un dominio inexplicable sobre mí, además, la brisa del mar, la comodidad del coche que corría veloz entre las clamedas, la misteriosa silenciosidad de la hora y las bebidas de la tarde, todo tenía no sé qué de encantador y sugestivo. 
Henri, sin que yo me hubiera dado cuenta llevaba en el coche unos grandes ovillos de hilo de Coquimbo, que es delgado y fuerte, y los había arreglado de tal manera que no gastásemos tiempo al llegar al subterráneo. Yo estaba pensativo. Henry lo conoció y trató de distraerme:

- Pero usted, doctor, crée que puede haber peligro o secreto alguno en bajar a esos subterráneos? -y luego sonriendo- en verdad, científicamente, me parece un disparate...

- Cientificamente es posible, le dije. He estudiado mucho el asunto. Ésto se aplica por medio de las localizaciones cerebrales. Al bajar al subterráneo se efectúa un verdadero proceso mental. Usied sabe que las localizaciones cerebrales tienen "relaciones e influencias entre si". Por ejemplo: la orientación y la visión, son dos sentidos que en cerebro se relacionan intimamente. Usted experiménielo. Al cerrar los ojos se despierta el sentido de la orientación. Se imagina usted, cuando cierra la vista, donde está tal objeio; "vé usted en su imaginación" la puerta por donde quiere salir y se dirige á ella. En este caso la orientación ha suplido á la visión y, unidos ambos fenómenos han dado el resultado que usted deseaba.

Observe usted, le decía á D Herauville, que un ciego de nacimiento no se podria orientar en una habitación, lo mismo que un hombre que entrá álella con los ojos abiertos y es vendado luego. Además hay oira localización que influye poderosamente sobre la de la luz; "lo def olfafo.

Esta es una tacultad un poco confusa aún pero que se estudia de la siguiente manera: Usted siente olor á violetas y se imagina usted las violetas azules, del mismo modo que ve usted sales tartáricas y se le "hace agua en la boca".

- Esto no me prueba, doctor, - me dijo D' Herauville- porqué no puedo bajar...

- Voy á concluir. He aquí la razón científica por la cual, usted al bajar al subterráneo no volverá más. Es una opinión de médico, pero una opinión privadísima...

(El coche se detuvo junto á la portada que da al cerrito, D' Herauville bajó primero, cogió sus masas de cuerda y enseguida bajé yó. La luna se había nublado un poco. El coche volvió hacia la población y nosotros principiamos á ascender).

- Continúe usted, doctor, me dijo Henry. 
- Bien... Decía que al bajar usted al subterráneo, deja de cercibir la influencia de la luz y como es natural, no habiendo luz que impresione sus ojos, el órgano no funciona y la localización cesa de trabajar, quedando á merced de cualquier acción refleja de las otras, pero al desaparecer la luz, el órgano de la orientación se despierta y entra en un período de gran actividad, porque usted cuando se encuentra á obscuras lo primero que hace en el subterráneo es tratar de orientarse. Tiene usted ya pues, un órgano, el de la vista, inerte y un órgano, el de la orientación, activo; es decir una localización, la de la vista, presionada por otra, la de orientarse. Ya éste es todo un sistema, un sistema casi gráfico.

El olfato, al entrar usted al subterráneo, trabaja poderosamente, á consecuencia de los olores especialísimos de ese lugar. Estas vibraciones de la pituitaria se reflejan en su lóbulo correspondiente y presionan al lóbulo inerte de la vista. Hay pues ya dos fuerzas activas actuando sobre una materia en reposo, que por esta influencia pierde su virtud, tal y como pierde su poder atractivo el imán calentado. Entonces á la necesidad natural de la luz sucede, por oposición, la necesidad de la obscuridad.

Porque si estando el sistema lobular en condiciones naturales, la luz necesita actuar para sostener el sistema; estando el sistema en un equilibrio invertido, á consecuencia de fuerzas extrañas, necesita actuar là Cosscuridad páráasostener este equilibrio.

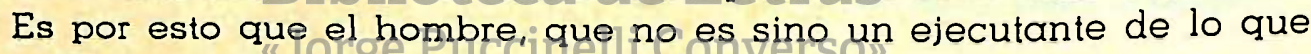
pasa en su cerebro, una vez que baja al subterráneo, lejos de salir á la luz, tiende á perderse en la obscuridad voluntaria, consciente, imperiosamente...

- ¿Y si de pronto volviera la luz?...

- Provocaría un desequilibrio que traería la locura. Esto que pasa, más ó menos, con las personas que reciben en condiciones delicadas una fuerte impresión, una noticia agradable ó dolorosa, pero intensa. Su sistema "psico-lobular" se desequilibra y la locura viene inmediatamente...

- Si eso fuera cierto, arguyó Henri, todas las personas que bajan á un sótano se perderían...

- No, porque este subterráneo tiene algo sobre los demás; sus olores peculiarísimos, que yo atribuyo á la cercanía del mar y á la gran extensión de las galerías...

- Bajaré sin embargo... 
- Piense usted, Henri, que nadie que haya bajado ha vuelto á subir jamás, piense usted en el Rosso, recuerde usted el pavor de Fiorenzi, sea usted cuerdo, no baje. Henri no contestó.

Habíamos llegado á lo alto del cerro. La Luna, Francinette, tenía ese color verde horrible y sugestionador. Color de alucinación, de fiebre, de sueño, de éter. Yo pienso que sólo allí tenía ese tono la luna. ¡Y qué bellísimo era! Decididamente tenemos una fibra especial, un sentido determinado para la luz de los astros, y un sentimiento para cada tonalidad de ellos. Bien sabe usted que el rojo provoca la ira; el azul provoca el reposo; el amarillo, el temor; el negro, el misterio. Pero estas sensaciones son vulgarísimas y ya usted sabe que se perciben por la vista.

Mas estas luces de la luna no entran por la vista, van más allá, se meten en los nervios, en las fibras, en la sangre, en los huesos. Creo que no obran como color sino como atracción y el color que tenía la luna aquella noche era un color verde metálico que inducía, no me cabe la menor duda, á lo insondable, á lo misterioso, á lo horrible. Entonces yo sentí la necesidad, hasta el deseo de que Henri bajase y sin decir más le acompañé en silencio.

La ciudad se exiendia blancionallinestros pies" en un silencio religioso. Henri recuerda la frase de Albert Samain:

..."dans la lenteur douee d' un soir des derniers jours".

Avanzamos en silencio, entramos en la ciudad y estábamos pálidos y trágicos. Tal vez no teníamos miedo sino el presentimiento de algo horrible. Estábamos atentos al menor ruido y no nos atrevíamos voltear la cara. La luna nos bañaba de blanco y así fuimos atravesando las calles empedradas, los portales derruídos y llegamos por fin á la piedra donde yo oí los golpes de Rosso. ¡Tal vez teníamos miedo! Nos detuvimos y nos pusimos a escuchar. De pronto se le abren á Henri los ojos, esos ojos de gato, claros y pavorosos, y me toma del brazo oprimiéndome fuertemente. Se inclina y me dice al oído débil, muy debilmente:

- ¿Siente usted?... Esos golpes...

- Sí siento, Henri- ¡Los golpes de Rossol...

- ¡Pero son ligerísimosl... 
Entonces sentí íntegra, palpitante, fiel la escena de Rosso. ¿Por qué grande locura había consentido en volver á este lugar? Un temblor nervioso me poseyó. Sentí que el alma se me escapaba. Henri me dijo como consultándome:

- ¿Qué piensa usied que hagamos?...

Maquinalmente le dije:

- Seguir...

$Y$ seguimos. Pasamos por unos portales, luego por unas escaleras enormes y entramos á una plazoleta: Entonces me di cuenta. Aquella era la plaza de la Santa Inquisición. En los restos del edificio había aún santos en los nichos de los muros. La puerta entreabierta y despedazada dejaba entrar rayos de luna y en la serenidad de su secular abandono, las cornisas, las torres, los ornamentos de los capiteles, proyectaban sobre el piso sombras que daban miedo.

D'Herauville rezó los versos de Samain:

L' ame fatigué aux siecles lui réspond dans cette lasitude indecible de l' heure"...

Yo no le interrumpí y seguimos avanzando. Pasamos muchas callejuelas y salimos á una esplanada donde había muchos huecos que debieron ser hechos por árboles -ahora no había ninguno en la ciudad- y seguimos hasta llegar al llegar al río que desliza sus aguas mansamente, Casivsins hacer ruido. La luna se copiaba íntegramente en el agua. Llegamos al puente. ¡Qué encantadora y amarga noche, Francinettel Llegaba hasta nosotros el vaho fresco del río, el aire terroso, de las cosas olvidadas de esa ciudad muerta, y la luz divina y verde de la luna que dibujaba esa arquitectura colonial, encantadora, vieja y rica entre la que éramos como dos almas de esos tiempos.

- ¡El río!, -dijo Henri- ¡Debe ser profundo!... ha muerto.

- El ríoj - dije yó como un eco- Es lo único que aún no

Y seguimos, seguimos silenciosos sobre la ciudad callada, sobre esa gran ciudad en ruinas donde no había flores ni árboles, ni buhos ni habitantes. Sólo había la luna acompañándonos y provocando en nosotros ese estado de alma en el que uno se olvida de lo real y sigue como un sonámbulo las órdenes de un interior misterioso que nos induce. 
Henri volvió á musitar como una oración el verso, evocador y divino:
"I' ecoule... et peu à peu, voicí, sur les flost bruns, vers les grands ponts dressés lábas comme des portes, que des barques de songe, oú sommeillent des mortes, s' eloignent dans la nuit sur des anciens parfums"

Por fin hemos llegado á la plazuela donde debe hallarse la entrada á los subterráneos. Efectivamente, Francinette, allí está la gran boca abierta, tal y como la dejara Rosso hace dos años. Llegamos. Entonces comienza la operación. Henri silencioso saca sus ovillos de hilo, la anuda y se amarra la cintura. Me ofrece el resto del hilo y los ovillos que debo ir desenvolviendo á medida que él baje.

No cabe duda, si yo me presto á esa operación voy a ser más que su cómplice, su asesino. Yo sé, yo sabía Francinette, que si Henri entraba no saldría jamás. Yo estaba convenido de que iba á perder á mi amigo y que de mí dependía su vida, debí oponerme, negarme, luchar á viva fuerza, - pero- $¡$ Oh momento! La luna estaba verde, más verde que nunca. Su luz me ofuscaba, me obsesionaba. Entre mi espíritu nervioso había algo que no puedo describir, pero que, á fuerza de darme miedo, me daba una sensación tan agradable, tuna fruición tan íntima, una corriente que iba desde mi corazón hacia todo mi cuerpo como una culebrilla, deliciosamente. ¡ Ya luna incitándome! Verde, divinamente verde, criminal, pero encantadoramente verde.

Henri pisó el primer escalón. Sacó el reloj y bajando hasta que su pecho estuvo al nivel del piso me dijo:

- Son las doce y media. Espéreme hasta la una.-y me dió la mano.

Yo me arrodillé para estrecharla y un vaho horrible salió del pozo. No tuve fuerzas para decir nada á Henri. Lo vi bajar un escalón, otro, y otro y lejos de gritar, de llamarle, de salvarlo, lo dejé irse hundiendo, poco a poco y ví perderse su sombra en el fondo de aquel pozo siniestro y maldito. Cuando ví que se había perdido, cuando me sentí solo en la ciudad muerta, un frío intenso se apoderó de mí. Me di cuenta de todo como si saliera de un sueño profundo, me acerqué más al agujero, me incliné sobre él y casi metiendo la cabeza, empecé á dar gritos horriblemente, con todas mis fuerzas: 
— ¡Henri!... ¡Henri! .. ¡ ¡Henri!...

Mi voz se perdió en las galerías y el eco fue repitiéndose de muro en muro, bajo la tierra.

- Perdóneme usted, Francinette, culpe usted a la luna; Henri D' Herauville, su amigo de la infancia, su novio, mi compañero, mi queridísimo Henri, había desaparecido para siempre.

\section{VII}

\section{LA HORA NEGRA, FRANCINETTE}

Por un momento estuve atento al menor ruido. El cordel corría entre mis manos á medida que Henri avanzaba en el corazón de la tierra. Yo sabía que cada vuelta de ovillo era una nueva distancia que me separaba de él para siempre. ¡Estaba tan convencido de que Henri no volvería á luz!

Sin embargo esperé unos minutos más. Ya mi naturaleza iba á estallar. Tenía el hilo entre los dedos, puesta toda mi alma en el tacto, para percibir cualquier señal de aviso, pues habíamos acordado con Henri que, si se sentía mal ó se perdía, tiraría de la cuerda para avisarme.

Pero el hilo corría, corría hacia el fondo negro del pozo. Corría, corría y henri no volvía á salir. Quise volver a llamarlo, me acerqué cíanto pudecal pożo y, alemeter en él la cabeza para gritar su nombre sentí - al menos he creído sentirlo- que tiraban de la cuerda con insistencia.

Tiraba no había duda y yo seguía dando cuerda, pero - joh qué impresión, Francinette! - cuando voltée la cara para destorcer el hilo que se había enredado, me encontré que el hilo se concluía. Tres metros más y yo no habría tenido ya ninguna comunicación, habría perdido para siempre sobre la tierra á Henri. Antes, hasta ese momento, yo estaba con él moralmente, porque mi imaginación corría sobre el hilo e iba a perderse en el fondo misterioso del subterráneo donde me imaginaba á mi amigo; pero cuando se concluyese la cuerda ¿qué lazo nos uniría?

Volví a sentir que tiraban de la cuerda nerviosamente $y$, con el tirón se gastaron dos metros más. No cabía duda: yo debía dejar y socorrer á mi amigo. Cualquier otra persona habría bajado, tal vez, teniendo la cuerda aún entre las manos; pero yo no 
me resolví. Pensé que siguiendo la cuerda, llegaría á donde estaba Henri y ¿quién sabía si lo encontraba? Quise todavía esperar y por fin, un tirón más débil, me arrebató la cuerda de las manos y yo ví cómo se fue resbalando el hilo, cómo se acababa el último metro, como si verdaderamente, estuviera asistiendo a las agonías de mi amigo.

Al concluirse la cuerda pensé aún en entrar, tal vez era tiempo para salvarle, pero la luna caía de lleno sobre la ciudad, y en el subterráneo iba á seguir un misterio, una locura, una cosa que me arrebataba, sombras indecisas, animales, huesos; riquezas tal vez. Abajo se extendía un mundo de locos, de seres extraños que ya no conocían la luz, de seres que se reproducían tal vez en el misterio insondable de una noche eterna. Habría corrientes de agua tumultunas que arrastraban a los exploradores, vapores malsanos que los enloquecerían, quién sabe si había allí debajo animales monstruosos que chupaban la sangre.

Todo esto me venía á la memoria atropelladamente, mientras el extremo de la cuerda entraba y se perdía en el pozo. En tanto, arriba, sobre la tierra se notaba la luna con su encantadora luz verde, bañando esa ciudad misteriosa. Arriba, sobre la tierra estaba el río, los antiguos palacios los monasterios derruidos, los lienzos, los dorados vestigios de una muerta civilización, pero detrás de todo esto estaba el mar inmenso sembrando de barcos, estaba la ciudad nueva con sus malecones, sus muelles, sus avenidas, sus hoteles y sus mujeres su barrio de extranjeros y sus salones de música y baile.

¡Piensa demasiado! Mi imaginación iba á estallar. Tuve miedo. Miedo de todo, de mí mismo, miedo de cosas invisibles.

Dudé un momento todavía y quise bajar pero no tuve bastante valor. Entonces vi de nuevo la luna, verde, verde, verde. El cielo de un azul clarísimo se había coloreado como el agua de mar vista en un vaso. Debía ser ya muy tarde y yo, poseído de horror indecible voltée la cara sin mirar el pozo y regresé, de prisa, apuradísimo, como un criminal por el centro de las calles y de las plazoletas, temiendo acercarme demasiado á los edificios y atisbando las sombras de estos que proyectaba la luna.

Quise dar la vuelta para no tocar con la piedra del Rosso y me perdí en un laberinto de callejuelas. No volveré á sufrir más que aquella noche. Cuando creía haber encontrado el camino mehallaba en un patio inmenso, especie de caballeriza. Quise sa- 
lir de él y me interné en el resto del edificio arruinado. Como un poseído subí á una escalera de piedra y no le podría decir Francinette, cómo bajé. Estaba casi loco y así corrí por las calles, me perdí por las plazoletas, torcí por las esquinas, y, ya cansado, sin esfuerzo, febril, sudoroso, en un estado de incapacidad física y mental, me dejé caer, sin ver nada, en el suelo.

Cuando me serené un poco examiné el lugar: estaba en la plaza del subterráneo. Otra vez, como si Henri me hubiere atraído. Sin darme cuenta había pasado el puente y había tornado á la plazoleta. Ya la luna declinaba: media hora más y yo me habría quedado á oscuras en aquel infernal laberinto. Rápidamente tomé una decisión: salir por el camino que conocía. Así lo hice. Tomé mucha prisa temeroso de que me dejase la luna y volviendo á cada diez pasos la cara para convencerme de que todavía me alumbraba.

Así llegué hasta la piedra del Rosso y aquí, otra vez, Francy, los golpes fatales sonaban, lejos, pero muy lejos. Entonces no pude más. Tuve miedo y eché á correr con todas mis fuerzas, subí al cerro casi arrastrándome, y antes de emprender la bajada me aterroricé. La luna ya no alumbraba y la ciudad estaba envuelta en una sombra total. Nada se veía. Entonces no tuve miedo, porque, al otro lado del mar, bajando el cerro, la ciudad nueva alumbraba y el puerto, lleno de luces, me acompañaban. Allí estuve gozando not secpor qué, alegrándome no se de que, pero yó, Francinete, me alegraba en ese momento.

Empecé a bajar. El aire del mar me daba de lleno en la cara $\mathrm{y}$, sereno, - sereno en medio de esas horas funámbulas- me acordé de Henri, pensé en la responsabilidad que tenía yo sobre mí, como médico, como amigo íntimo de él. Aquella tarde nos habían visto juntos y usted comprende que mi condición era delicadísima respecto a los demás, y, fuera de eso, yo mismo, íntimamente, me acusaba: si yo le hubiera impedido, Henri no habría bajado á las ruinas. Estaba pensando en esto cuando veo que un hombre, ya en la población, se acerca y me reconoce. Un frío intenso baña todo mi cuerpo. Me dice:

- Doctor, casi lo he desconocido. ¿Qué se hace usted a estas horas?... - Le hemos buscado desde las cinco para que despache usted un barco y he tenido que hacerlo yó. - Mejor así, si le he evitado una molestia porque ya sale el "Jeroboam"...

- ¿Cómo? - le interrumpí- ¿Han depedido el "Jeroboam?"... 
- A las siete de la tarde... Hubo un pequeño inconveniente: faltaba un pasajero francés, M. de D' Herauville, pero, naturalmente se crée que ha querido quedarse en el puerto...

Llegué á casa y me arrojé desesperado sobre la cama. Allí éstaba, sobre el velador, desde la víspera, el libro de Henri abierto en la página del silencio. Maquinalmente, fastidiado, cerré el libro que lució su carátula en la cual aparecía el título mundial de la novela "Misterio". Por la ventana entreabierta que daba hacia el mar ví la bahía lejana y pude notar tres luces que en. triángulo se perdían sobre la curva inmensa del mar.

- El "Jeroboam", pensé.

Voltée la cara y no me acuerdo más de aquella noche.

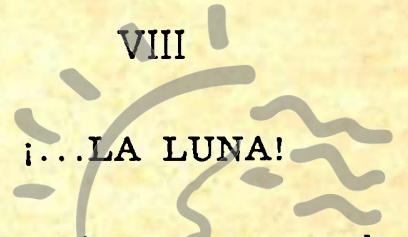

Al día siguiente - Francinette, encantadora amiga - tomé el barco que me condujo adonde nos conocimos y donde nos habríamos casado, á no haber yo sabido ocho días antes, que usted era prometida de Henri y que yo tuve la culpa de esa gran desgracia.

Yo sé que él me perdonará - donde esté- el haberle dejado bajar a los subterráneos, perdóneme usted también porque yo quería á Henri. Fue un buen amigo para mí, tenía un gran corazón y un gran talento, pero ila lunal...

¡Oh Francinettel Desconfíe usted de las noches de luna, no busque nunca las ciudades viejas, ambas cosas conducen al misterio, á la locura, al crimen, a la fatalidad. La luna es la virgen de los alucinados, de los poelas, de los neurasténicos, de los locos y de los criminales. Su mismo espíritu es dudoso y ambiguo, "dime ¡Oh reina de la noche si en tu lánguido semblante - palideces hay de vicios ó blancuras de inocencia".

- La luna es de todos aquellos seres que no tienen en la vida sino su alma incomprensible, soñadora y grande como las horas de la luna, como el misterio blanco de la luna, como la luz verde, criminal y lujuriosa de la luna... 
IX

\section{LA CARTA}

Ya nos acercamos á Río de Janeiro.

Pronto anclará el barco y podré enviar á usted mi correspondencia. También le envió la maleta de Henri que pude sacar del "Insular" y que he guardado religiosamente. Ya es la hora. Diviso desde el barco los muelles y los malecones de este gran puerto muy parecido aunque enormemente más grande que el de $C^{\prime \prime}$ ". Yo no bajaré á tierra. Ahora cierro la carta y me voy a popa de donde veo las hélices que mueven las entrañas del mar, mientras el "Atica" se desliza, esbelto y poderoso, entre los barcos anclados, los diques enormes y mohosos, y una barquilla de pescadores que oculta al sol con su latina y blanca vela...

\section{Biblioteca de Letras "Jorge Puccinelli Converso"}

